\title{
Psychosocial and Cultural Barriers to Communication Skills Learning in a South East Asian Medical School
}

\author{
Andrew L.S. Foong \\ University of Tasmania
}

\author{
C.F. Sow \\ International Medical University
}

With continuing reports of poor communication skills, this study set out to explore reasons as to why medical undergraduates in a medical school should have difficulties with communication skills learning for competent professional practice of international standards. Volunteers were recruited from third year undergraduate medical students to participate in focus group interviews to provide feedback on their experiences with communication skills learning. Six different groups were set up before saturation point was reached, with each group comprising of between six to eight participants. Qualitative analysis of data by coding and categorization threw up a range of insights into the students' challenges with communication skills learning. Two primary areas explored comprised of barriers to communication skills learning and how lecturers could help students improve communication skills learning. The findings highlight participants' acknowledgement of the issue of communication skills to be a problem. They presented a range of insights into the psychosocial and cultural perspectives that were barriers to their learning. Various teaching and learning factors were highlighted as reasons for challenges to the learning of communication skills. They could serve as guidance for educators and education managers to take on board for enhancing communication skills learning and as indicators for further studies.

Keywords: teaching, learning, medical students, communication skills, psychosocial, cultural, barriers

\section{INTRODUCTION}

The issue of competent communication skills has been presented as challenges globally (Dupre \& Williams, 2011; Thomas, Piquette \& McMaster, 2016) to a whole range of professional groups (Fong, Sidhu \& Chan, 2014; Ting et al, 2017). With regard to medical education several studies in the West have reported on the obstacles of communication skills and its significance as one of the core skills (van den Eertwegh et al, 2014; Deveugele, 2015; Peron et al, 2015) reinforced by it being a part of the core curriculum in every medical school in the United Kingdom and USA (Brown, 2012). As a professional grouping studies in the Asian context have highlighted challenges such as in Indonesia (Claramita et al, 2013), Nepal (Moore, 2009), Sri Lanka (Marambe et al, 2012), and Malaysia (Wahab \& Ismail, 2014; Cheong et al, 2015). 


\section{BACKGROUND}

It is now well known that effective communications can have positive impacts on health outcomes for patients (Ha \& Longnecker, 2010; Hojat et al, 2011 ) but, reports suggest medical students in Malaysia tend to be poor at communication skills (Wahab \& Ismail, 2014; Cheong et al, 2015) raising questions as to why it should be so? A recent study demonstrated that medical students' attitudes towards communication skills may have impacts on their success (Foong et al, 2019), or otherwise, with assessments such as through the Objective Structured Clinical Examination (OSCE), a multi-dimensional practical examination of clinical skills which includes interpersonal communication skills, decisionmaking and management of patients (Harden et al, 1975; Harden \& Gleeson, 1979). Students with poor communication skills risk being eliminated if they are unable to demonstrate the required level of competence in interpersonal skills (Laidlaw \& Hart, 2011).

Although, it has been widely accepted that attitudes influence behaviors (Fishbein \& Azjen, 1975; Azjen, 1991; Eagly \& Chaiken, 1993) studies on attitudes and communication skills learning have presented with mixed results (Marambe et al, 2012; Wright et al, 2006). While studies have suggested medical students' attitudes, values and feelings to be a major factor (Dyche, 2007; Lumma-Sellenthin, 2009), it would be prudent to determine the reasons why medical students may be having difficulties with the learning of what are core skills to enable competent practice and for evidence-based interventions to be considered. For instance, one question is whether medical educators might be unknowingly failing in their responsibilities to students such as through their delivery of learning approaches and activities. Although students may be aware of the relevance of communication skills to medical practice, they may not value the communication skills component of the undergraduate medical curriculum for various reasons including an emphasis on the biomedical model (Marambe et al 2012) and the concept of patientcentered care still not being widely accepted in Asian countries (Chatterjee \& Choudhury, 2011). Whilst attitudes are seen to be a determining factor for poor communication skills, what remains unclear are the intervening education processes that may be propagating them. This is a pertinent question as the curriculum for this study cohort has a large communication skills component. It may also highlight the point of whether teachers are conscious of their impacts on the formation of attitudes of students such as in the manner of management of the learner, learning tasks, and learning context (Ulug et al, 2011). The significant impact of teachers on students' development cannot be underestimated. However, how aware are teachers of their impacts? In that regard, students' perspectives on what they see to be the issues that contribute to the challenges in their learning of communication skills would be important. Such perspective-taking could ameliorate the notion that just because teachers have provided their teaching activity, does not mean that students would have learned. Such perspective-taking could serve as constructive evaluative feedback to guide teachers towards reflection and better understanding of their students' needs and so be student-centered with productive learning outcomes. With that in mind, along with insights into the culture of teaching and learning in the South East Asian context, an extrapolation of pertinent issues is suggested for highlighting necessary meaningful actions. Taking Malaysia as an example in the South East Asian context, education practices have tended to be traditionalistic in nature. It has suited, and, seen to be compatible with the culture in the collectivistic sense deeply embedded in segments of the society (Cheng, 2000). However, to operate in the $21^{\text {st }}$ century the need is $4 \mathrm{Cs}$ creativity, communication, collaboration, and critical thinking (Kivunja, 2014).

\section{AIM OF STUDY}

The aim of the study is to identify the factors that inhibit effective health care communication skills learning and development of medical students in a medical school in Malaysia. 


\section{Rationale for Study}

The rationale is for the evidence base to inform an action plan of interventions for implementation to improve communication skills learning and development to enhance clinical practice that is fit for purpose.

\section{Participants}

Ethics clearance for the study was obtained from the University Research and Ethics Committee (IMU JC NO: IMU326/2015). Purposive sampling involved recruitment of participants from third year undergraduate medical students who had been through various clinical learning courses including communications skills. Recruitment was by a call for volunteers following their attendance at a lecture. They were allocated to the focus group slots that would be convenient to them.

Explanations were provided for the need to elicit their experiences and perceptions of the teaching and learning issues and processes that they consider to be challenges to their learning of communication skills. They were informed of the data collection process being done through small group discussions, i.e., focus groups. Informed consent was obtained from all individual participants included in the study. Each focus group comprised of six to eight participants, the numbers considered conducive for such data collection (Krueger \& Casey, 2009). As willing volunteers, participants engaged actively in the discussions and each of the group discussions were facilitated by the same researcher (AF) in a seminar room. Responses were recorded and a scribe made written notes. Each session lasted approximately one hour. Through the iterative process we felt that we had reached saturation point by the time we got to the sixth focus group.

\section{Methods}

The focus groups sought to elicit data based on two questions aimed at exploring the barriers to their learning of communications skills. The questions are:

1. What do you think are the barriers to your learning of communication skills?

2. How do you think your lecturers might be able to help you improve your communication skills?

Participants were informed of the procedure for conducting data collection based on a structure within the two areas of exploration as listed above. Responses were elicited until saturation was reached, and the iterative process followed on with each of the focus groups. Qualitative analysis of data was undertaken by an initial coding process and re-coding for categorization. Through the process of inter-rater checks (Daly \& McDonald, 1992) by two researchers, descriptions of meaning identified from the focus group responses were categorized through content analysis (Krippendorf, 1980). Emergent categories were then identified and classified with on-going comparisons undertaken to derive common categories that became evident within each of the two areas of exploration.

\section{Findings from Focus Groups}

With an aim towards enhancing clarity, the findings from the focus group discussions are presented according to data derived from the two main areas of exploration. Pertinent discussion points in relation to each of the two areas will be presented within each of them. A summarising discussion will then be presented towards the end of the paper.

\section{WHAT ARE THE BARRIERS TO LEARNING OF COMMUNICATION SKILLS?}

In response to the first question, "What do you think are the barriers to your learning of communication skills?", a wide array of thoughts was thrown up with insights into the obstacles encountered by the respondents' own experiences and beliefs. Eight dimensions emerged from the analysis as outlined below and could be referred to as Enervating Inhibitors: 
1. Personal attitudes: Participants reported an attitudinal challenge with the "lack of personal initiative" or having "no initiative from students as there are no penalties or rewards from facilitators". It stretches to the more disturbing trait of "indifference, and not willing to learn as they think they are good enough and do not see the need to improve" in those skills, or, "they do not find a need to express themselves" to patients or others. They also acknowledged that there may be the matter of "ignorance and not being aware of communication problems" nor the "importance of communication with others".

2. Cognitive abilities: It is a challenging situation when they don't have enough knowledge base to be able to function appropriately in terms of being able to engage with patients meaningfully. Quite simply, they "don't know what to ask", and so be able "to keep up with the conversation". For that reason, "if we do not have enough information/facts, it is better to keep quiet".

3. Cultural values: This is an area with numerous repeated comments to indicate the challenges of the Asian culture and values in relation to education. Repeatedly, the "Asian mentality" was highlighted as being at the crux of the matter, whereby students feel deep-rooted inhibition as a result of "upbringing and schooling which emphasizes obedience" towards those in authority with the resultant "lack of freedom to express" themselves. For instance, "as students in Malaysia, there is less talking", and we "don't question teachers, elders and seniors". This is pervasive all the way from "primary to secondary school". The "do not question culture" is overwhelming to the extent that even as children, i.e. "since young, we are told not to argue or fight back, especially towards elders". They are often "expected to do tasks well or be punished" with longer term imprinted psychological effects.

4. Self-efficacy: It "depends on confidence level of a person". There is an impression that upbringing, or possibly insidious cultural values such as outlined above brings forth the "sense of inferiority - not good enough". They "don't want to look stupid", and as a result are "being too self-conscious leading to the tendency to talk in rigid robotic ways" with implications of negative evaluations.

5. Anxieties: Respondents expressed "fear of being judged by everyone", and also of "making mistakes", in class when they should speak. It is compounded by being conscious of "others looking at you weirdly". The issue of "how others may react, e.g. patients becoming angry" is important to them. There is an overly concern about "how people will judge you". The "fear of being put down or criticized" seems to be overwhelming. For some reason, they tend to be "inhibited by criticism". That includes constructive feedback as indicated by comments that "we are not used to constructive criticism". For some reason(s), they do not have the "ability to accept constructive criticism". Rather than accepting them with good grace, "some students perceive the constructive criticism as an act or show of hatred from other students".

6. Cultural inhibition: In relation to the "Asian mentality" described above, there is an implicit pressure to not "stand out" as they "do not want to make a fool of yourself". . Apparently, there is a "tall poppy syndrome", whereby, in the "Malaysian education system, shorter poppies gang up against the one who speaks up or stands out" leading to the sense of inhibition. This sense of inhibition can often be demonstrated by the way in which students "approach teacher individually" at the end of the lecture.

7. Teaching and Learning: The general explanation for their difficulties with communication skills are suggested to be due to "lack of exposure". By that, they mean the "lack of opportunity to communicate with real patients" for meaningful learning that is not an artificial act. "Normally we practice with simulated patients, but not with real patients". It does not help that they are "not natural due to scripted requirements". "Teacher-student 
barriers" were identified as an obstacle, too. For instance, some lecturers "do not engage readily", and in some cases their "short-tempered responses" are "discouraging". The "lack of feedback from lecturers and peers" do not help in providing them with "reaffirmation/reassurance" to encourage further learning to take place. That may be illustrated in the case where "In semester one, they wanted to know if they are asking the right questions in the right way" to reinforce learning. There is a perceived "lack of emphasis on communications in the curriculum". It seems to be the case "from school, through to tertiary education" level.

8. Group dynamics: Compounding the cultural values and psychological inhibition is the problem of "peer pressure or group dynamics" influencing behaviors. The feeling is that there is "better learning in small groups" as there would be "less opportunities for practice because of big groups". There are "big groups of 10:1 patient", that "restricted learning because of just watching friend take history as too many students to one patient - watching others take history is not the same as taking it yourself". There is acknowledgement of how their communication skills could be improved by speaking the English language but they "tend to stick to 'gang' of friends instead of mixing around with others" to help improve.

Clearly, the students have expressed their discomfort with the attitudes of their peers such as their dismissiveness towards the essence of communication skills in professional practice (Foong et al, 2019). Such observations raise broader questions including the appropriateness for such students in the field of medicine and selection criteria into medical school. The possibility of doctors over-estimating their capabilities in communication skills continues to be an issue (Ha \& Longnecker, 2010). The other side of the coin is the behavioral inhibitory factor, particularly amongst the East Asians that appears to be a significant barrier (Rubin et al, 2006). The expression of "Asian culture" was repeated in all the six focus groups and its prominent inhibitory effects emphasized. They comprise of the attributes acquired through enculturation by developmental processes such as that of prevailing pervasive schooling culture, where students are molded to be passive receivers of didactic teaching by authoritarian teachers. Such an approach tends to suppress expressiveness (Cheng, 2000; Hellsten \& Prescott, 2004) and therefore communications development. The pervasiveness of such enculturation permeates into such aspects as their self-concepts with impacts on self-efficacy and anxieties that serve to propagate the self-fulfilling prophecy thereby reinforcing psychological inhibition.

When one is lacking confidence due to heightened awareness of the weakness, the tendency to be more self-conscious of it is increased. The result could be a feedback mechanism that brings about anxieties over one's performance of the task and impeding learning. Thus, being observed produces evaluation apprehension (Geen, 1985). Such self-awareness of the weakness could also lead to the tendency towards being negative towards the idea of conducting communication activities. There is also the possibility of invoking the mental defense mechanism of repression or denials with the problems and so, not acknowledging them or addressing them accordingly. Appropriate help is neither sought nor given. Hence, it is important to consider not just the cognitive processes, but also the psychosocial aspects such as feelings and attitudes of learners.

In the context of medical education, largely with values driven by western perspectives and expectations, students are required to take on board that, in a globalized world, competent interpersonal communication skills in clinical practice is an imperative for positive care outcomes. It is also with acknowledgment of the essence and sensibilities of cultural competence (Dogra et al, 2015).

In terms of teaching delivery, it is suggested that some care and preparation would go a long way towards helping to reinforce positive learning experiences that would nurture confidence in the required skills, rather than negative experiences that reinforces weaknesses and the negative attitudes that may be permeated, along with the range of spillover effects. Given the predominant inhibitory factor of "Asian culture", considerations for safe learning environments such as the fostering and development of conducive group dynamics are suggested to facilitate productive learning. 
The sense of incompetence in conducting their roles as a result of inadequate technical knowledge to communicate effectively have been demonstrated by responses in terms of their complementary functions. They are compounded by what they see as teaching and learning approaches and systems, which exacerbates the barriers to be overcome (Benbassat et al, 2003). It would therefore be interesting for a study with final year students with the acquired clinical knowledge to enable performance of communication skills. More importantly, from the bigger picture perspective, the message is for relevant authorities to seriously consider the need for schooling practices and systems that would help break the cycle of suppression, albeit unintended.

\section{HOW CAN LECTURERS HELP WITH IMPROVING COMMUNIATION SKILLS?}

To explore participants thoughts on their teachers' roles in facilitating their learning of communication skills, they were asked the question, "How might lecturers help improve your communication skills? The responses encompassed the following five dimensions that could be referred to as Enabling Facilitators:

i) Teachers' attitudes: Lecturers' approaches make a difference to students. Essentially, " $b e$ more friendly to students", and not create the "hierarchical barrier" that does not help with a safe and conducive learning environment. It would help for lecturers to reflect on the "manner of delivery of constructive feedback" such as with their "tonality", and "be more flexible and encouraging, such as how they react to your mistake, without making us feel stupid". Lecturers "should not intimidate" and should "encourage questions rather than be judgmental" to facilitate learning.

ii) Teachers' capabilities: "Communication skills is actually very subjective", and sometimes "lecturers are unable to guide". For example, they can be "contradictory and inconsistent". The nature of subjectivity is such that "different lecturers have different ways and perspectives on communication skills. This causes confusion to students". For example, "one lecturer may do it this way, but another lecturer doesn't agree with the way". In the end, students listen to the lecturers and decide for themselves which way is preferable. "We are told that we need to be empathetic, but not shown how to be empathetic". They are simply "words but not application" that can show us how to empathize, appropriately.

iii) Learning process: There is a need to consider the "learning process" for communication skills rather than outcomes to guide productive learning. The current "focus on the use of a checklist of scripted situations", as perceived by students are "too artificial" for effective learning. The impression is that the "nature of OSCE is such that explanation of procedures and processes are important, including provision of productive feedback on where improvement is needed". Currently, "feedback regarding communication skills are inadequate". The provision of "generalized feedback" such as "you can improve in your communication skills" are not of help to students. When feedback is "not constructive, we do not know our mistakes". It is useful to be provided with "rationales, i.e. reasons for one as opposed to another" to facilitate effective meaningful learning.

iv) Opportunities for learning: - The existing group sizes of ten students are felt to be too large, and the suggestion is for "smaller groups of about four students, so that everyone has a chance to practice communication skills with simulated patients" and obtain "feedback from lecturers". "Smaller groups for quality rather than quantity" to allow for more meaningful feedback to reinforce learning. Additionally, students seek "increased sessions". For example, "with sexual history taking, there is only one opportunity for practice in Semester 3, and then re-visited once in Semester 5. There is no follow-up with real patients for history taking such as with sexual history" to reinforce learning. 
v) Opportunities to perform: The suggestion is for students to be exposed "to real hospital settings" to be able to "deal with real patients". In doing so, "lecturers can demonstrate to us in the real settings" to make learning more meaningful and therefore easier to incorporate. Currently, the impression is that there are "no real practice supervision in hospital wards and clinics", and the question is whether students are "making the same mistakes and not realizing them".

The responses in this section highlighted several factors that could be worked on to improve the overall student experience in the learning of communication skills. Lecturers and clinical teachers are in key pivotal positions for inculcating productive learning by the way they exude positive behaviors students can emulate through vicarious learning (Bandura, 1965; 1977). Additionally, processes and systems could be considered to guide meaningful learning that would avoid challenges such as 'robotic' questioning, which students recognize as being common. That raises various questions including that of whether students are being 'forced' into situations which they themselves recognize to be wrong, but at the same time at a loss to deal with. This challenge has also been reported by medical residents in postgraduate training in the Netherlands (van den Eertwegh et al, 2014).

Teachers, by virtue of their positions in a hierarchical collectivistic society (Oyserman, Coon \& Kemmelmeier, 2002) such as in South East Asia, have huge impacts on the way in which students respond and interact, in their presence. Greater self-awareness on their part is sought in relation to their sense of self and ultimately, the interpersonal dynamics and relationships, which could encourage or inhibit learning. The most powerful influence on empathy development happens to be that of clinical teachers as positive role models (Wear \& Zarconi, 2008; Tavakol, Dennick \& Tavakol, 2012).

Greater consideration is also sought for the learning process, including the structuring of activities and timely feedback to guide learning. Lecturers may think they are doing the right thing based on their experiences in their cultural context. The question, though, is whether what they have 'taught' in the classroom are achieving the desired effect for students' learning of communications skills. It is a situation of the teaching being driven by teachers as opposed to what has been espoused for students to be the main drivers of their learning (Schwartzstein \& Roberts, 2017). Just because the teacher has taught something in a classroom does not mean students have learned them (Sklar, 2017). Further to that is the issue where academic staff are employed to teach but are not trained nor qualified to teach (Maphosa \& Mudzielwana, 2014). It highlights the possible role of comprehensive teacher training programs for effectiveness as medical educators because a good doctor does not necessarily equate to a good teacher.

\section{Discussions}

Data derived from the focus groups provided rich insights alluding to the intricate dynamics that may be involved and thoughts for further studies. Whilst disparate in nature the issues are amenable to various examinations for learning and teaching considerations. Although the study is directed towards the South East Asian context, the literature suggests similarities to the wider East Asian perspective (Cheng, 2000; Rubin et al, 2006; Tran 2013). Likewise, although the study is based on health care communication skills learning for medical students the issues raised appear to be in common with communication skills learning for other fields (Fong et al, 2014; Helyer, 2015; Maphosa. \& Mudzielwana, 2014)

With the commonly held belief that students in South East Asia tend to be passive learners by their reticent behavioral manifestations, teachers would gain to be mindful that it does not mean they are incapable or simply disinterested as individuals. Reports, including numerous anecdotally, have indicated that Malaysian students are inclined to not say anything during lecture discussion sessions to the point that even when a teacher should ask a general question, the class would become deadly silent (Dick \& Robinson, 1995). Such behaviors were suggested to be due to their affect and language conversational abilities (Sawir, 2005). Other causes for reticent behaviors include shyness; parental influence and defective learning in the family and school; distressing experience; social and ethnic groups (Jones 1999; Phillips, 1997). The insights raised in this study reinforces the general sentiments highlighted by earlier studies. Given that background, and the emerging ethos of personalized learning (Sebba et al, 2007), one 
challenge for teachers appear to be that of how they may adapt to address the identified needs as existing educational systems and approaches no longer fit the world we live in today (Guldbaek, Vinkel \& Broens, 2011; Maphosa \& Mudzielwana, 2014).

East Asians tend to hold collectivistic values that influence their behaviors. The Chinese appear to be more prone towards those values and, so, may well be more pronounced with their behavioral manifestations, such as when communicating in the presence of elders or being passive, reticent, and over-dependent on the teacher (Tsui, 1996; Rubin et al, 2006). As a collectivistic society, the East Asian culture values modesty and social harmony to the extent that they tend to be reserved about judging themselves positively (Falbo et al, 1997). It is a double-edged sword in contemporary societies influenced by Western individualistic values which encourage vocalization of one's achievements with pride. Creative approaches in teaching and learning in the South East Asian learning environment have significant roles.

The influence of teachers as models to impart the significance of communication skills and motivate students cannot be underestimated as they can adversely impact the development of professionalism (Kenny et al, 2003). Students do make evaluations of teachers' attitudes and get a sense of their competence to impact on their own desire and motivations towards their learning of the skills. For a subject largely with humanistic elements, it is not unreasonable for students to expect their teachers to demonstrate behaviors consistent with the ethos of humanism (Maheux et al, 2000). Interestingly, in a Lebanese study, interns rated medical expertise most highly compared with humanistic empathy and collaborative relations with patients and colleagues, prompting suggestions for greater emphasis on such skills in medical education (Yazigi et al, 2006), given their inter-dependence in clinical practice for positive patient outcomes.

The literature on educational theories and practices espouses the application of various methods for enhancement of learning. The issues identified in this study suggest the re-visiting of them for incorporation in the facilitation of communication skills learning. For instance, when one considers the novice to expert model of development (Benner, 1984), an application that could be productive is the extension of practical knowledge through Vygotsky's (1980), zone of proximal development. It comprises of the range of skills the student can perform with help and guidance from others but cannot yet perform independently. With support mechanisms through scaffolding, skills can be learned (Obukhova, \& Korepanova, 2009) and built on through a spiral curriculum, a concept introduced by Bruner (1960), later applied in medical education (Harden et al, 1997; Harden \& Stamper, 1999) and reinforced by the need for work on curriculum design with communication skills continuing into the clinical years of training (Brown, 2012).

The long-held narrative that East Asian students are reticent and passive learners are not helpful as research evidence suggest that many Asian students do have a strong desire to engage in classroom activities (Cheng, 2000). Attitudes and behaviors formed through many years of enculturation such as schooling will not change overnight (Hakim-Larson \& Menna, 2015) such as by being in higher education. The need for appropriate strategies towards cultivating a learning environment that exudes a sense of 'safety' that would help address attributes such as inhibitions may well go some way to enhance group dynamics that encourages shared learning. Teachers tend to assume that when they deliver a teaching session, students should be able to pick up on them (Sklar, 2017).

What has been established is that competition and achievement pressure is high in Asian classrooms (Falbo et al, 1997). Rather than competition, the culture and ethos of collaborative learning could be developed to encourage more shared learning that would benefit students, not just from the education, but also mental health perspective. Collaborative shared learning could serve to enhance further communication skills as more engagement takes place.

This study has explored issues related to improving learning for communication skills. In the process, it implies thoughts on application of practical teaching considerations. They are referred to here, as the " 2 E's" of communication skills learning - Enervating Inhibitors; Enabling Facilitators. What they can do is to encourage educators to be systematic and sensitive observers of learning as it takes place every day in their education environment (Dielissen, Bottema, Verdonk \& Lagro-Janssen, 2011). The nature of 
communication skills is such that it is not necessarily clear-cut for measuring quantitatively. It is more about determining if students have developed qualitatively richer or deeper understanding of the actions observed. That assessment and judgment is dependent on the teachers' breadth and depth of experience, and skills. For reasons such as this, the primary responsibility for student learning of communication skills falls on teachers to take the lead. Having a curriculum that outlines inclusion of communication skills do not in themselves imply the provision of education provision of the required quality by appropriately trained teachers. If so, it could become tokenistic, with far-reaching implications.

\section{CONCLUSION}

It is suggested that this study has met its intended aim to identify the factors that play a role in inhibiting effective communication skills learning and development of medical students in South East Asia. It has also served to provide the evidence base needed in accordance with the rationale for this study to inform an action plan of interventions directed towards improving communication skills learning and development to enhance clinical practice that is fit for purpose. Given that large numbers of students from South East Asia embark on their higher education in the West, the findings could provide educators in the West with insights that could be taken into consideration in their education provision and discourse which would otherwise tend to be seen only from the Western lens.

\section{ACKNOWLEDGEMENT}

The authors would like to express their gratitude to the medical students who very kindly gave up their time to contribute actively and insightfully to the study.

\section{REFERENCES}

Ajzen, L. (1991). The theory of planned behavior. Organizational Behavior and Human Decision Processes, 50, 179-211. https://doi.org/10.1016/0749-5978(91)90020-T

Bandura, A. (1965). Vicarious processes: A case of no-trial learning. Advances in Experimental Social Psychology, 2, 1-55. https://doi.org/10.1016/S0065-2601(08)60102-1

Bandura, A. (1977). Social learning theory. New York: General Learning Press.

Benbassat, J., Baumal, R., Borkan, J.M., \& Ber, R. (2003). Overcoming Barriers to Teaching the Behavioral and Social Sciences to Medical Students. Academic Medicine, 78(4), 372-380.

Benner, P. (1984). From Novice to Expert. Menlo Park, Ca: Addison Wesley Publishing Company.

Brown, J. (2012). Clinical communication education in the United Kingdom: Some fresh insights. Academic Medicine, 87(8), 1101-1104. https://doi.org/10.1097/ACM.0b013e31825ccbb4

Bruner, J.S. (1960). The process of education. Cambridge. M.A.: Harvard University Press.

Chatterjee, S., \& Choudhury, N. (2011). Medical communication skills training in the Indian setting: Need of the hour. Asian Journal of Transfusion Science, 5(1), 8-10. doi: 10.4103/09736247.75968

Cheng, X. (2000). Asian students' reticence revisited. System, 28(3), 435-446. https://doi.org/10.1016/S0346-251X(00)00015-4

Cheong, K.C., Hill, C., Fernandez-Chung, R., \& Leong, Y.C. (2015). Employing the 'unemployable': Employer perceptions of Malaysian graduates. Studies in Higher Education, 41(12), 2253-2270. https://doi.org/10.1080/03075079.2015.1034260

Claramita, M., Nugraheni, M.D.F., van Dalen, J., \& van der Vleuten, C. (2013). Doctor-patient communication in Southeast Asia: A different culture? Advances in Health Science Education, 18, 15-31. https://doi.org/10.1007/s10459-012-9352-5

Daly, J., \& McDonald, I. (1992). Covering your back. Strategies for qualitative research in clinical settings. Qualitative Health Research, 2(4), 416-38. https://doi.org/10.1177/104973239200200404 
Deveugele, M. (2015). Communication training: Skills and beyond. Patient Education \& Counseling, 98(10), 1287-1291. https://doi.org/10.1016/j.pec.2015.08.011

Dick, R.C., \& Robinson, B.M. (1995). Intercultural dimensions of teaching speech communication in Malaysia: Negotiating the Malays' malaise. Paper presented at the Biennial Convention of the World Communication Association, Vancouver, British Columbia, Canada.

Dielissen, P., Bottema, B., Verdonk, P., \& Lagro-Janssen, T. (2011). Attention to gender in communication skills assessment instruments in medical education: A review. Medical Education, 45(3), 239-248. https://doi.org/10.1111/j.1365-2923.2010.03876.x

Dogra, N., Bhatti, F., Ertubey, C., Kelly, M., Rowlands, A., Singh, D., \& Turner, M. (2015). Teaching diversity to medical undergraduates: Curriculum development, delivery and assessment. AMEE Guide No. 103. Medical Teacher, 38(4), 323-337. https://doi.org/10.3109/0142159X.2015.1105944

DuPre, C., \& Williams, K. (2011). Undergraduates' perceptions of employer expectations. Journal of Career and Technical Education, 26(1), 8-19.

Dyche, L. (2007). Interpersonal skill in medicine: The essential partner of verbal communication. Journal of General Internal Medicine, 22(7), 1035-9. doi: 10.1007/s11606-007-0153-0

Eagly, A., \& Chaiken, S. (1993). The psychology of attitudes. Fort Worth, TX: Harcourt, Brace.

Falbo, T., Poston, D.L., Jr., Triscari, R.S., \& Zhang, X. (1997). Self-enhancing illusions among Chinese schoolchildren. Journal of Cross-Cultural Psychology, 28, 172-191. https://doi.org/10.1177/0022022197282003

Fishbein, M., \& Ajzen, I. (1975). Belief, attitude, intention and behaviour: An introduction to theory and research. Addison-Wesley: Reading, Massachusetts.

Fong, L.L., Sidhu, G.K., \& Fook, C.Y. (2014). Exploring $21^{\text {st }}$ century skills amongst postgraduates in Malaysia. Procedia - Social \& Behavioural Sciences, 123(20), 130-138. https://doi.org/10.1016/j.sbspro.2014.01.1406

Foong, A.L.S., Sow, C.F., Ramasamy, S., \& Yap, P.S. (2019). Pre-tertiary education, ethnicity and attitudes of Asian medical undergraduates towards communication skills. International Journal of Medical Education, 10, 1-8. DOI: 10.5116/ijme.5c30.988d

Geen, R.G. (1985). Evaluation apprehension and response withholding in solution of anagrams. Personality \& Individual Differences, 6(3), 293-298. https://doi.org/10.1016/01918869(85)90052-2

Guldbaek, J., Vinkel, H. B., \& Broens, M.G. (2011). Transforming pedagogical ethos into an effective learning environment. Denmark: OECD.

Ha, J.F., \& Longnecker, N. (2010). Doctor-Patient communication: A review. The Ochsner Journal, 10(1), 38-43.

Hakim-Larson, J., \& Menna, R. (2015). Acculturation and Enculturation from: Handbook of Arab American Psychology Routledge. Retrieved February 8, 2019, from https://www.routledgehandbooks.com/doi/10.4324/9780203763582.ch3

Harden, R., \& Gleeson, F. (1979). Assessment of medical competence using an objective structured clinical examination. Medical Education, 13(1), 39-54. https://doi.org/10.1111/j.13652923.1979.tb00918.x

Harden, R.M., \& Stamper, N. (1999). What is a spiral curriculum? Medical Teacher, 21(2), 141-143. https://doi.org/10.1080/01421599979752

Harden, R.M., Davis, M.H., \& Crosby, J.R. (1997). The new Dundee medical curriculum: A whole that is greater than the sum of the parts. Medical Education, 31(4), 264-271. https://doi.org/10.1111/j.1365-2923.1997.tb02923.x

Harden, R.M., Stevenson, M., Wilson Downie, W., \& Wilson, G.M. (1975). Assessment of Clinical Competence using Objective Structured Examination. British Medical Journal, 1, 447-451. https://doi.org/10.1136/bmj.1.5955.447

Hellsten, M., \& Prescott, A. (2004). Learning at university: the international students experience. International Education Journal, 5(3), 344-351. 
Helyer, R. (2015). Learning through reflection: the critical role of reflection in work-based learning. Journal of Work-Applied Management, 7(1), 15-27. https://doi.org/10.1108/JWAM-10-2015-003

Hojat, M., Louis, D.Z., Markham, F.W., Wender, R., Rabinowitz, C., \& Gonnella, J. (2011). Physicians' empathy and clinical outcomes for diabetic patients. Academic Medicine, 86(3), 359-364. https://doi.org/10.1097/ACM.0b013e3182086fe1

Jones, J.F. (1999). From silence to talks: Cross-cultural ideas on students' participation in academic group discussion. English for Specific Purposes, 18(3), 243-259. https://doi.org/10.1016/S08894906(97)00059-8

Kenny, N.P., Mann, K.V., \& MacLeod, H. (2003). Role modelling in physicians' professional formation: Reconsidering an essential but untapped educational strategy. Academic Medicine, 78(12), 12031210.

Kivunja, C. (2014). Innovative pedagogies in higher education to become effective teachers of $21^{\text {st }}$ Century skills: Unpacking the learning and innovations skills domain of the new learning paradigm. International Journal of Higher Education, 3(4), 37-48.

http://dx.doi.org/10.5430/ijhe.v3n4p37

Krippendorf, K. (1980). Content analysis: An introduction of its methodology. Beverly Hills, CA.: Sage.

Krueger, R.A., \& Casey, M.A. (2009). Focus groups: a practical guide for applied research (4). Thousand Oaks, California: Sage.

Laidlaw, A., \& Hart, J. (2011). Communication skills: an essential component of medical curricula. Part I: Assessment of clinical communication: AMEE Guide No. 51. Medical Teacher, 33(1), 6-8. https://doi.org/10.3109/0142159X.2011.531170

Lumma-Sillenthin, A. (2009). Talking with patients and peers: medical students' difficulties with learning communication skills. Medical Teacher, 31(6), 528-534. https://doi.org/10.1080/01421590802208859

Maheux, B., Beaudoin, C., Berkson, L., Cote, L., Des Marchais, J., \& Jean, P. (2000). Medical faculty as humanistic physicians and teachers: the perceptions of students at innovative and traditional medical schools. Medical Education, 34(8), 630-4. https://doi.org/10.1046/j.13652923.2000.00543.x

Maphosa, C., \& Mudzielwana, N.P. (2014). Professionalization of teaching in universities: A compelling case. International Journal of Educational Sciences, 6(1), 65-73. https://doi.org/10.1080/09751122.2014.11890119

Marambe, K.N., Edussuriya, D.H., \& Davaratne, K. (2012). Attitudes of Sri Lankan Medical Students toward Learning Communications. Education for Health, 25(3), 165-171. DOI: 10.4103/13576283.109796

Moore, M. (2009). What do Nepalese medical students and doctors think about patient-centred communication? Patient Education \& Counseling, 76(1), 38-43. https://doi.org/10.1016/j.pec.2008.11.018

Obukhova, L. F., \& Korepanova, I. A. (2009). The Zone of Proximal Development: A Spatiotemporal Model. Journal of Russian \& East European Psychology, 47(6), 25-47. doi:10.2753/RPO10610405470602

Oppenheim, A.N. (1968). Questionnaire Design and Attitude Measurement. Heinemann: London.

Oyserman, D., Coon, H.M., \& Kemmelmeier, M. (2002). Rethinking individualism and collectivism: An evaluation of theoretical assumptions and meta-analyses. Psychological Bulletin, 128(1), 3-72. http://dx.doi.org/10.1037/0033-2909.128.1.3

Peron, N.J., Sommer, J., Louis-Simonet, M., \& Nendaz, M. (2015). Teaching communication skills: Beyond wishful thinking. Swiss Medical Weekly, 145(0708). https://doi.org/10.4414/smw.2015.14064

Phillips, G.M. (1997). Reticence: A perspective on social withdrawal. In J.A. Day, J.C. McCroskey, J. Ayres, T. Hopf \& D.M. Ayres (Eds.), Avoiding communication: Shyness, reticence and communication apprehension (2nd ed., pp. 129-150). Cresskill, N.J.: Hampton Press. 
Rubin, K.H., Hemphill, S.A., Chen, X., Hastings, P., Sanson, A., Coco, A.L., . . \& Cui, L. (2006). A cross-cultural study of behavioural inhibition in toddlers: East-West-North-South. International Journal of Behavioural Development, 30(3), 219-226. https://doi.org/10.1177/0165025406066723

Sawir, E. (2005). Language difficulties of international students in Australia: The effects of prior learning experience. International Education Journal, 6(5), 567-580.

Schwartzstein, R.M., \& Roberts, D.H. (2017). Saying Goodbye to Lectures in Medical School Paradigm Shift or Passing Fad? New England Journal of Medicine, 377(7), 605-607. https:// DOI: 10.1056/NEJMp1706474

Sebba, J., Brown, N., Steward, S., Galton, M., James, M., Celentano, N., \& Boddy, P. (2007). An investigation of personalised learning approaches used by schools. Research Report 843. London: Department for Education and Skills.

Sklar, D.P. (2017). Just because I am teaching doesn't mean they are learning: Improving our teaching for a new generation of learners. Academic Medicine, 92(8), 1061-1063. https:// doi: 10.1097/ACM.0000000000001808

Tavakol, S., Dennick, R., \& Tavakol, M. (2012), Medical students' understanding of empathy: A phenomenological study. Medical Education, 46(3), 306-316. https://doi.org/10.1111/j.13652923.2011.04152.x

Thomas, A., Piquette, C., \& McMaster, D. (2016). English communication skills for employability: The perspectives of employers in Bahrain. Learning and Teaching in Higher Education: Gulf Perspectives, 13(1), 1-17. http://dx.doi.org/10.18538/lthe.v13.n1.227

Thurstone, L.L. (1938). Primary mental abilities. Chicago: University of Chicago Press.

Ting, S.H., Marzuki, E., Chuah, K.M., Misieng, J., \& Jerome, C. (2017). Employers' views on importance of English proficiency and communication skills for employability in Malaysia. Indonesian Journal of Applied Linguistics, 7(2), 315-327. https://doi.org/10.17509/ijal.v7i2.8132

Tran, T. T. (2013). Is the learning approach of students from the Confucian heritage culture problematic? Educational Research for Policy and Practice, 12(1), 57-65.

Tsui, A. (1996). Reticence and anxiety in second language learning. In K. Bailey \& D. Nunan (Eds.), Voices from the Language Classroom (pp. 145-167). Cambridge University Press: Cambridge.

Ulug, M., Ozden, M.S., \& Eryilmaz, A. (2011). The effects of teachers' attitudes on students' personality and performance. Procedia - Social and Behavioural Sciences, 30, 738-742. https://doi.org/10.1016/j.sbspro.2011.10.144

van den Eertwegh, V., van Dalen, J., van Dulmen, S., van der Vleuten, C., \& Scherpbier, A. (2014). Residents' perceived barriers to communication skills learning: Comparing two medical working contexts in postgraduate training. Patient Education \& Counseling, 95(1), 91-97. https://doi.org/10.1016/j.pec.2014.01.002

Vygotsky, L. S. (1980). Mind in society: The development of higher psychological processes. Cambridge, MA: Harvard University Press.

Wahab, A.W.A., \& Ismail, N.A.S. (2014). Communication skills and its impact on the marketability of UKM graduates. International Journal of Higher Education, 3(4), 64-71. http://dx.doi.org/10.5430/ijhe.v3n4p64

Wear, D., \& Zarconi, J. (2008). Can compassion be taught? Let's ask our students. Journal of General Internal Medicine, 23(7), 948-953. Retrieved from https://link.springer.com/content/pdf/10.1007\%2Fs11606-007-0501-0.pdf

Wright, K.B., Bylund, C., Ware, J., Parker, P., Query, J.L., \& Baile, W. (2008). Medical student attitudes toward communication skills training and knowledge of appropriate patient-provider communication: A comparison of first year and fourth year medical students. Medical Education Online, 11(1), 1-10. https://doi.org/10.3402/meo.v11i.4594

Yazigi, A., Nasr. M., Sleilaty, G., \& Nemr, E. (2006). Clinical teachers as role models: perceptions of interns and residents in a Lebanese medical school. Wiley Online Library, 40(7), 654-661. https://doi.org/10.1111/j.1365-2929.2006.02502.x 